\title{
Contribution on Control Strategies of Flow-On-Demand Hydraulic Circuits
}

\author{
M. Scherer, M. Geimer and B. Weiss* \\ Karlsruhe Institute of Technology, Chair of Mobile Machines, Karlsruhe, Germany \\ E-mail: martin.scherer@kit.edu,marcus.geimer@kit.edu,bweiss@weiss-can-sps.de \\ *Weiss Mobiltechnik GmbH, Rohrdorf, Germany
}

\begin{abstract}
The development of an innovative flow-on-demand electrohydraulic system for mobile forestry cranes is described in the present paper. To overcome functional principle related weaknesses of conventional hydraulic-mechanical Load-Sensing systems, this work breaks up the control pressure difference related dependence of the delivered oil flow. Rather the swiveling angle of the displacement pump is calculated by summing up the single consumer oil flows corresponding to the velocity requests of the machine operator. For the electrohydraulic spool valves, several advanced control strategy concepts are discussed, each of which leading to an energy efficient artificial but controlled undersupply. The energy saving potentials are derived from a characteristic forestry crane duty cycle via dynamic simulation methods. Further on, the system shall be set up in a prototype crane to validate simulation results and to pave the way to the market by demonstrating the system performance.
\end{abstract}

Keywords: flow-on-demand, flow control, Load-Sensing, electrohydraulic, forestry crane, dynamic simulation, control strategy, energy efficiency, operability

\section{Introduction and Objectives}

Electrohydraulic systems offer new possibilities regarding energy efficiency and operability. A rising number of electrohydraulic components available on the market leads to their advancing application in mobile machines, as manufacturers, machine owners and operators show increasing confidence in the reliability of these complex systems. In recent years an interest shift from pressure controlled hydraulic systems to directly flow controlled systems, requiring electrohydraulic components, may be identified from academic publications. Despite being a relatively young field of research, nevertheless these flow controlled systems themselves have shown a slight evolution over the last few years [1] [2] [3] [4] [5]. With researchers from internationally distributed institutions taking up the issue and adding their ideas [6] [7] [8] (cf. chap. 2.2 and 2.3) flow controlled systems have reached a sophisticated status. Nevertheless these systems still play a negligible role in the industry of mobile hydraulics. Merging the most promising flow sharing solutions from relevant publications with own approaches, at the Karlsruhe Institute of Technology (KIT), a public funded, application-oriented research project is conducted to investigate the benefits of an electrohydraulic flow-on-demand control. This innovative hydraulic system for a forestry crane is compared to a conventional hydraulic-mechanical Load-Sensing (LS) system in terms of energy efficiency. In a first step, the system is represented using simulation methods and later validated with a hydraulic test bench and a prototype. To ensure a smooth introduction on the market, especially for small batch applications like forestry machines, an unique characteristic of the project is the sole use of components available off-the-shelf.

\section{Theoretical Considerations}

The motivation for research on flow-on-demand systems is based on the omnipresent striving for improved energy efficiency in general as well as on considerations concerning operability improvements in particular. To understand the advantages of flow controlled applications, initially hydraulic-mechanical Load-Sensing systems are discussed, representing the state-of-the-art in a wide range of mobile hydraulic applications as of today.

\subsection{Technical Reference - Load-Sensing}

Load-Sensing hydraulic control systems adjust the pump pressure and/ or the flow rate to the demand of the consumer loads. The first Load-Sending systems were developed in the mid-seventies in the US [9]. The intention was to reduce the power losses of constant flow or constant pressure systems.

In principle Load-Sensing systems can be divided in two categories, the Open-Center (OC) and the Closed-Center (CC) systems. Open-Center Load-Sensing systems use a fixed displacement pump and regulate the pump pressure by 
an inlet pressure compensator in the valve assembly. This unloading valve is operative to bypass excess pump flow to the tank. Thus the efficiency is related to the ratio of the pump flow rate $Q_{\mathrm{P}}$ to the summation $\Sigma Q_{\mathrm{L}}$ of the flow rates that are demanded by the hydraulic loads [10]. Therefore the OCLS systems generate high losses when the load pressure is high but flow rate demand is relatively small [5]. For equally loaded consumers, the best point of the degree of efficiency is calculated by eq. (1):

$$
\eta_{t h}=\frac{1}{1+\frac{\Delta p_{L S}}{p_{L}}} \cdot \frac{\Sigma Q_{L}}{Q_{P}}
$$

Due to this disadvantage, OCLS systems have de facto lost their market relevance to CCLS systems. To reduce the losses and improve the efficiency, these hydraulic systems are provided with variable displacement pump. The pump is regulated by a pressure controller as well as a flow rate controller. The control pressure margin $\Delta p_{\mathrm{LS}}$ between the highest load pressure $p_{\mathrm{L}}$ and the pump pressure $p_{\mathrm{P}}$ is held constant over all operating points (see eq. (2)).

$$
\Delta p_{L S}=p_{P}-p_{L}
$$

Therefore the efficiency is not related to the flow rate [10]. The degree of efficiency is calculated by eq. (3), again the losses related to minor loaded consumers remain unconsidered in the equation:

$$
\eta_{t h}=\frac{1}{1+\frac{\Delta p_{L S}}{p_{L}}}
$$

To provide load independent flow rates and therefore consumer velocities and to prevent load interference between the hydraulic consumers, individual pressure compensators are installed either up- or downstream to the directional control valves. These pressure compensators ensure a constant pressure drop $\Delta p=$ const over the metering orifice, thus the flow rate is nothing but dependent on the restriction area $A_{0}$, corresponding to the valve spool position. This relation is described via the universal orifice formula (see eq. (4)).

$$
Q=\alpha_{D} \cdot A_{0} \cdot \sqrt{\frac{2 \cdot \Delta p}{\rho}}
$$

The so called pre- or post compensators show similar system behavior in normal operating mode, but differ in case of pump saturation. In these undersupply situations, the pre compensator layout causes only the consumer with the momentarily highest load to slow down or even stop, leaving the other consumers undisturbed. Whereas the technically complexer post compensators divide the flow rate in ratio to the nominal flow of the main valves, slowing down each consumer proportionally.

Exemplary, the hydraulic circuit of a LS system with two linear motors is shown in Figure 1.

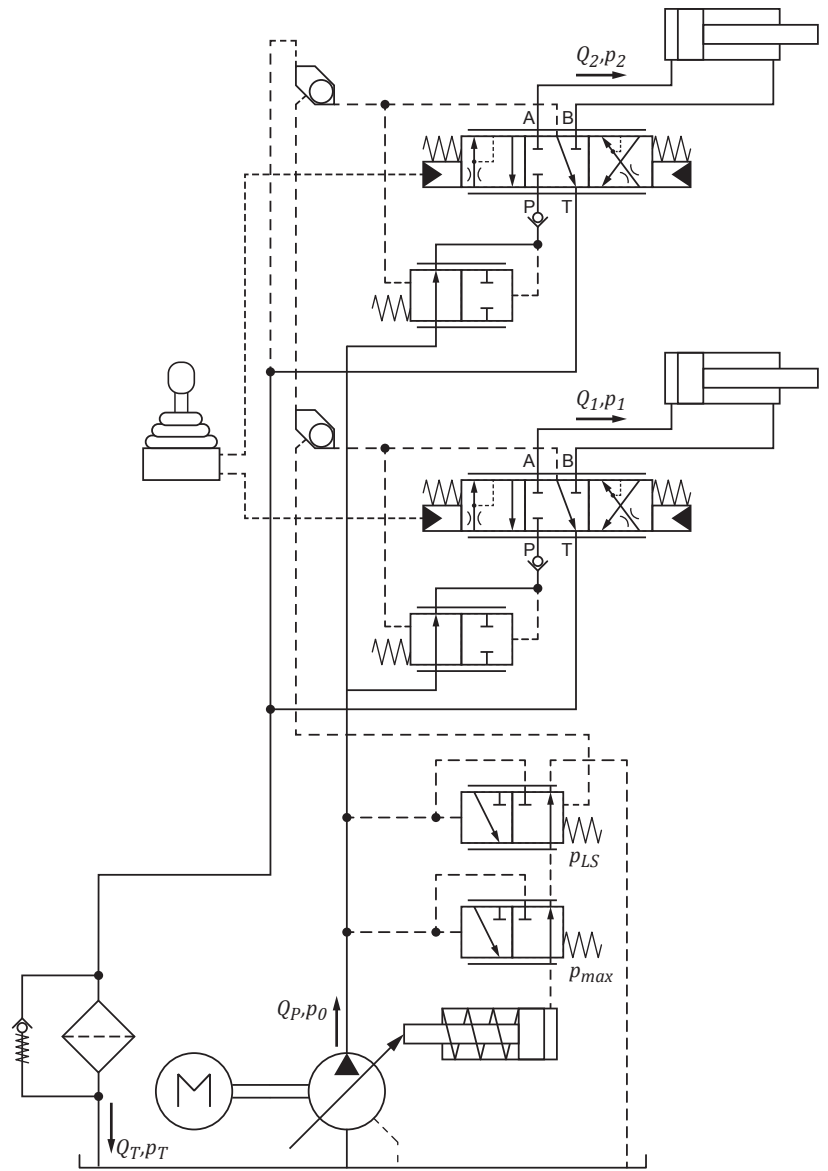

Figure 1: circuit layout of a CC hydraulic-mechanical Load-Sensing system with pre compensator

To ensure sufficient control performance and quick response times the control pressure margin $\Delta p_{\mathrm{LS}}$ between pump pressure and highest load pressure in conventional Load-Sensing systems is set to at least 20 bars, easily reaching 30 bars in systems with remote consumers entailing long load signal lines. As those signal lines form a closed hydraulic control loop, LS systems show a disturbing oscillation tendency.

Especially in partial load situations where the constant control pressure margin accounts for considerable ratios of the total energy demand, Load-Sensing hydraulic systems face efficiency disadvantages. The throttling losses are mainly linked to the pressure drop $\Delta p_{\mathrm{PC}}$ over the metering orifice of the highest loaded consumer, set by the related individual pressure compensator. This constant pressure drop is usually tuned in at ratios of $2 / 3$ up to $3 / 4$ of the total Load-Sensing functional principle pressure difference $\Delta p_{\mathrm{LS}}$, set by the flow rate controller of the pump. Thus, the pressure difference related power losses consist of throttling losses $P_{\text {Loss,thr }}$ and an additional functional principal share $P_{\text {Loss,fp }}$. In Figure 2 these losses are represented for the exemplary LS system with two consumers. 


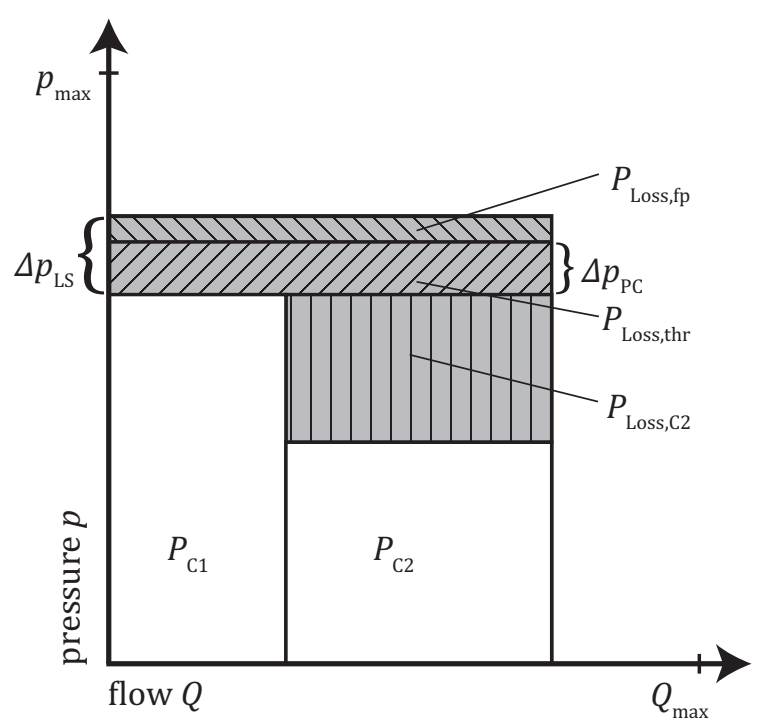

Figure 2: power losses of Load-Sensing systems

The throttling losses are made up by line resistances and pressure drops over the control edges of the directional control valve and pressure compensator of the consumer with the highest load. These losses are inherent in valve controlled hydraulic systems. In contrast, the functional principal losses may be omitted by changing from a pressure controlled system to a flow controlled system.

Another drawback of Load-Sensing systems is their poor cold start performance, also related to the signal lines and the hydraulic-mechanical controllers, a deficit that also becomes obsolete with the proposed flow-on-demand control.

\subsection{Flow-On-Demand Principle}

The basic idea behind the flow-on-demand principle is to calculate the required oil flow through the consumer velocity inputs of the electronic joysticks or by reading back the valve spool positions with the integrated displacement sensors. The aggregate flow, delivered by an electrohydraulic displacement pump, is to match the single flow demands precisely. The pump pressure settles itself according to the highest load pressure plus the pressure drop over the metering orifice and the inevitable line resistances. In comparison to Load-Sensing systems, a significant reduction of the pressure level may be achieved (see Figure 3). To ensure load independence of the system and accurate flow distribution, individual pressure compensators are installed. For smooth ease of control the pressure compensators are setup to keep a constant pressure drop of 7 bars over the metering orifices [5]. Together with the line resistances, this pressure drop accounts for the power loss margin $P_{\text {loss,thr }}$ of the flowon-demand system, which makes up about 30-40\% of the Load-Sensing principle related power losses of comparable LS systems. The decreased pressure level accounts for the saving potential of the power consumption $P_{\mathrm{sp}}$. Thus the degree of efficiency is calculated by eq. (5):

$$
\eta_{t h}=\frac{1}{1+\frac{\Delta p_{P C}}{p_{L}}}
$$

The losses related to the obligatory throttling of minor loaded consumers (eg. $P_{\text {Loss.C2 }}$ ) remain as weakness of valve controlled systems with shared pump usage, but are yet accepted as displacement controlled systems where each function has a dedicated pump [11] [12] [13] [14] have other drawbacks, especially concerning differential cylinder actuation, partial load situations and control dynamics.

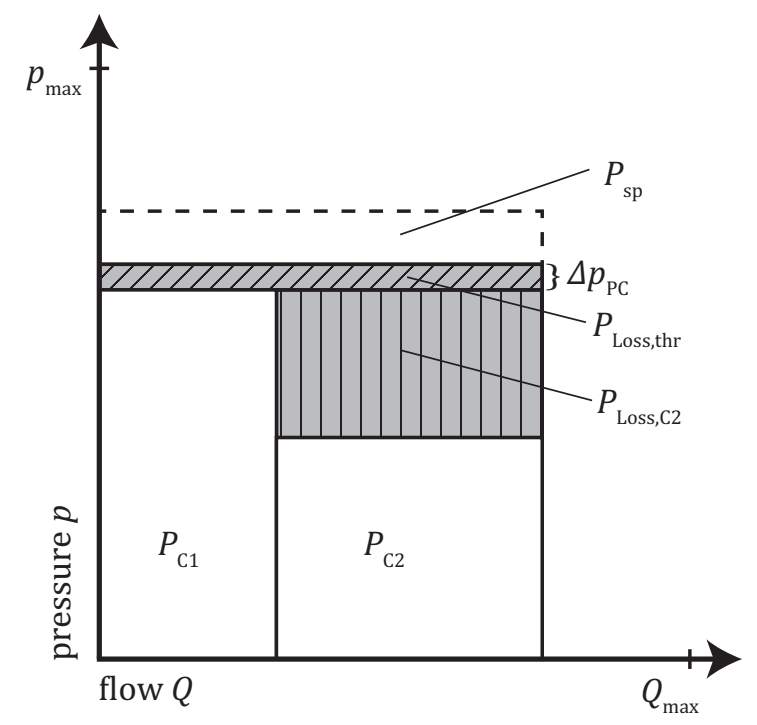

Figure 3: power losses of flow-on-demand system

To compare and to differentiate the proposed flow-on-demand system from related publications and from the current state-of-the-art, a preliminary discussion on terminology of hydraulic systems with direct pump displacement control is necessary. While the described functional principle differs only marginally, a wide variety of designations has been established. As development started in Germany, many expressions are in German language, where attention is to be paid to the marvelous linguistic distinction between 'Steuerung' and 'Regelung', which translate as 'open-loop' and 'closed-loop' control. Initial considerations were published by ZäHE [15] in 1993 under the expression 'Summenstromregelung', roughly 'aggregate flow control'. DJUROvic [1] refined the issue in 2007 under the proprietary Bosch Rexroth brand name 'EFM - Electronic Flow Matching', when suitable electrohydraulic components were finally available. In the same year, FEDDE [2] came up with his interpretation of the subject and named the system 'Bedarfsstromsteuerung' which contains the denotation 'Bedarf', meaning 'demand', for the first time. Following up on DJuRovic's work, FINZEL [5] frequently switched between 'Bedarfsstromregelung' and 'Flow Matching' but finally applied the acronym 'ELS' for 'Electrohydraulic Load-Sensing'. Which he explains with the preserved load-sensing functionality at least in the flow distribution section because the pressure compensators still compare the highest load pressure to the system pressure. In absence of the pressure 
dependency of the displacement control in the flow generation section, meaning the position of the swiveling angle of the pump has no pressure related closed-loop control, the denotation 'ELS' appears rather confusing. In international publications AxIN [7] and ERIKSSON [6] coined the most suitable phrase 'Flow Controlled System', with the latter likewise using 'Flow Sharing System' alongside.

Being linked to a single company or implying ambiguities, the authors resign from applying any of the identified expressions from literature and introduce the term 'flow-ondemand' control to characterize the presented hydraulic system for a forestry crane application.

As indicated, DJuRovic laid the basics for following interpretations of flow controlled system. He settled his research on ideas of Hesse [16] and Helduser [17] and developed an extensive classification for the design of directly displacement controlled hydraulic systems with multiple consumers per pump. He distinguished systems with open-loop control of the pump flow rate and directly or indirectly closed-loop controlled versions. Furthermore he groups pre- and post-compensated systems. In the assembled matrix, practical solutions are identified and studied in detail. Figure 4 shows the schematic of the previously described, principle Flow Matching application with open-loop flow rate control. The simplified illustration dispenses with representing the consumers. The directional valve is displayed as adjustment meter-in orifice, the return flow is not shown. The system gets along without any sensors and therefore depicts the simplest version of a flow control implementation. Unfortunately, the system shows inadequate behavior during operating states of under- or oversupply, that may occur due to erroneous flow rate aggregation, leakages or operating errors. Analogous to Load-Sensing hydraulics with pre compensators (cf. chap. 2.1), undersupply or rather unforced pump saturation, causes the consumer with the highest load

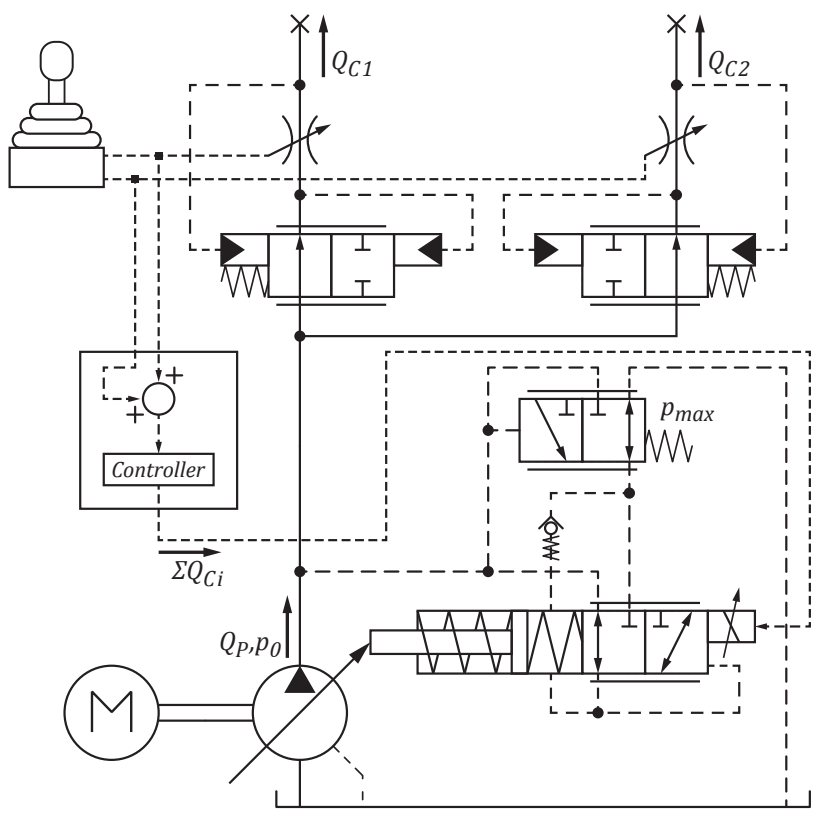

Figure 4: Open-loop control type Electrohydraulic Flow Matching with pre compensator [1] pressure to slow down or even stop. This behavior may be compensated by the operator. Recognizing the deviation, he will simply increase the velocity target-setting with the joystick. The major drawback arises from situations of flow oversupply. In this case the pressure drop over the metering orifice increases and the pre compensator shuts completely, preventing further consumer movement. The pump pressure increases to its maximum. A simple but energy inefficient workaround is the introduction of an inlet pressure compensator in the valve assembly, operative to bypass excess pump flow to the tank.

To maintain the efficiency advantage and to ensure a well tuned and distributed flow rate, DJUROVIC developed several closed-loop control strategies. A direct flow control is depicted in Figure 5. The introduction of a pump flow rate sensor serves to evade the over- and undersupply issues on the one hand. On the other hand, these sensors are expensive, fragile and generate throttle losses themselves.

Thus, indirectly controlled systems appear to be the better alternative. If the previously mentioned inlet pressure compensator is equipped with a translational sensor, the controlled variable for the pump flow rate is a straight shut compensator. A common disadvantage herewith, is the reintroduction of a hydraulic-mechanical closed-loop controller, entailing the drawbacks of a conventional Load-Sensing system. Another indirect control solution is to fit the individual pre compensators with translational sensors. Inherent to the functional principle, the compensator of the load-leading consumer opens the farthest. Consequently, the controlled variable for the pump flow rate is the completely opened position of the relevant compensator.

As flow controlled systems with conventional pre compensators require additional components and sensors to regulate flow distribution and keep up functionally in case of oversupply, the development of systems with flow sharing post

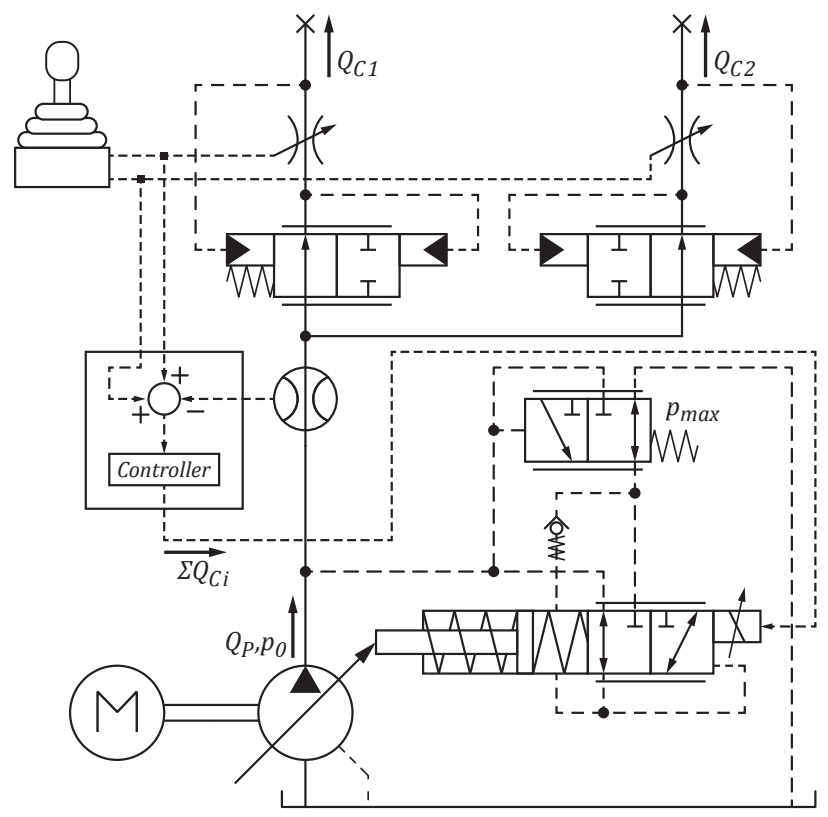

Figure 5: Closed-loop control type Electrohydraulic Flow Matching with pre compensator and flow rate sensor [1] 
compensators seems reasonable. Availability of the obligatory electrohydraulic directional valves, let to research on the topic by FInZEL [3] [5]. The corresponding schematic of an exemplary flow controlled hydraulic system with two consumers is shown in Figure 6.

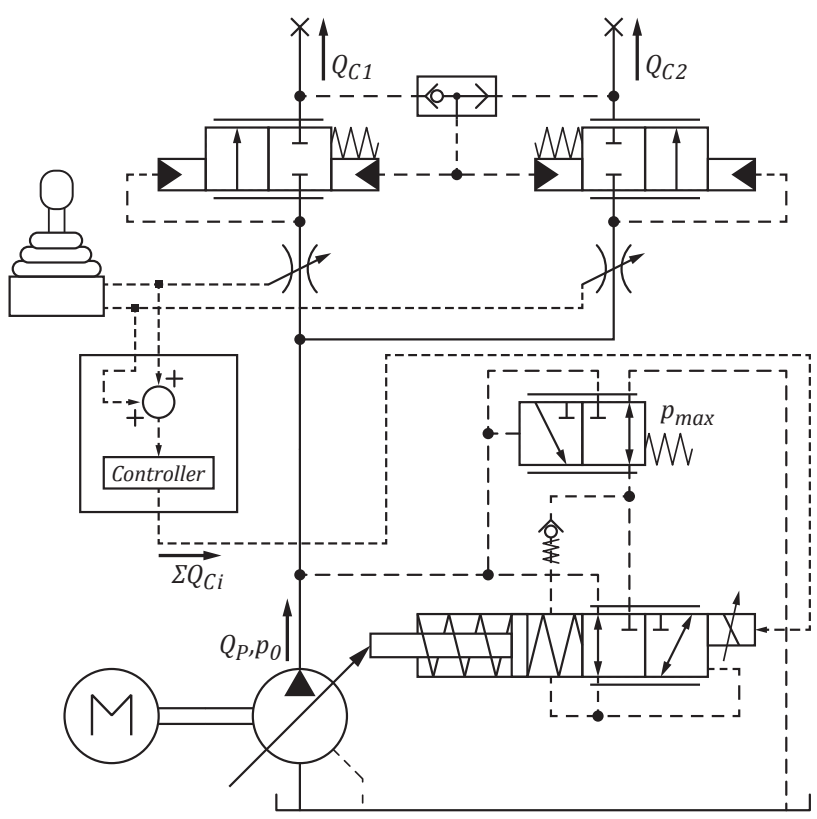

Figure 6: Open-loop control type Electrohydraulic Flow Matching with post compensator [5]

Not at all utilizing any hydraulic signal lines nor any sensors or electronic closed-loop controls, a robust and reliably system is achieved.

\subsection{Advanced Control Concepts}

To further improve the energy efficiency of flow controlled systems, the electronic control unit allows for several advanced control strategies. Without the LS-inherent pressure dependence of the oil flow delivered by the displacement pump, the system may be operated in a state of controlled undersupply. For this undersupply, different operating strategies are conceivable, all affecting control precision but further enhancing efficiency. DJUROVIC resigns from compensating leakages in valves and consumers into the pump flow rate calculation [1]. Generating a rather tad small oil flow the machine operator is to balance out inaccuracies by adjusting his flow demand. As FInZEL deploys post compensators with flow sharing properties, these compensators distribute the entire pump flow relative to the individual valve openings. This gives the control system one extra degree of freedom, that may be used to minimize the pressure drop across the metering orifices. FInZEL suggests to open the orifice of the load-leading consumer completely and to adjust the opening of the remaining orifices according to the demanded flow shares [5]. A similar approach is presented by FEDDE, only that the orifice openings of the minor loaded consumers are derived from a characteristic diagram by means of the pressure differences of the consumers currently in action [2]. AxIN comes up with a similar argumentation but uses the maximum restriction area of the consumer with the highest momentary flow demand. The other actuators use an increased restriction area in proportion to their flow requests [4]. The potential additional energy savings of those four advanced control concepts are investigated in a dynamic simulation model of the forestry crane (cf. chap. 4).

A novel control concept is being introduced to prevent flow oversupply in case of consumers reaching cylinder end stops. In this case the consumer velocity inputs and the actual consumer oil flows do not match any more. If the aggregate flow of the pump is solely calculated through addition of these consumer velocity inputs, the pump delivers too much oil into the systems, accelerating the residual consumers in an undesirable manner. To overcome the issue, the control valves are equipped with additional pressure transducers and electronic pressure limiting functions. Reaching an end stop, causes the consumer pressure to rise to its preset maximum. In turn the related control valve switches from flow control mode to pressure control mode, ignoring the joystick input and controlling the pressure by reducing the control edge opening. The respective closed-loop control is displayed in Figure 7.

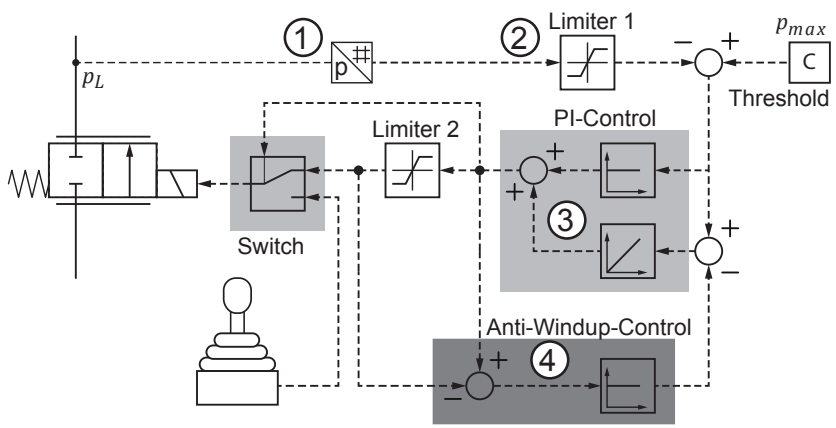

Figure 7: electronic pressure control

The load pressure $p_{\mathrm{L}}$ behind the valve is measured by a pressure transducer (1) and compared to a threshold. Due to a limiter (2), which sets the minimum value of the load pressure to the threshold, the comparator just passes a signal unequal to zero if the pressure is above the threshold. In this case, the error is conducted to a proportional-integral (PI) control. This provides accurateness for the maximum pressure values. The value behind this control switches, once it has reached a threshold, the command of the valve from the user to the pressure-control of the valve (3). Another limiter restricts the signal of the proportional-integral control, so the valve closes if the maximum pressure is reached. Due to the fact, that the valve is not constantly following the values of the PI-control, the stability of the system requires an anti-windup control (4). The anti-windup control subtracts the difference of the values before and after the limiter from the value leading to the integral part of the PI-control. Through the feedback of the anti-windup control, the value of the integral part of the PI-control will not grow through the limitation. To calculate the aggregate pump oil flow, no longer the velocity input is utilized but the flow corresponding with the valve spool position.

A further issue is the poor damping characteristic of a standard meter-out orifice, being firstly addressed by AxIN [8]. 
Especially concerning dragging loads, unwanted aftereffects may occur. As elaborated orifice design is the decisive factor, but not being detailed in the simulation models, the authors have included an innovative directional valve into the hydraulic test bench layout (cf. chap. 5). The concerned device has a segmented valve spool, which allows for independent activation of the control edges $P$ - $A$ from $B-T$, respective $P-B$ from $A-T$. The flow rate is calculated according to the meter-in orifice position, which is related directly to the desired consumer velocity. To avoid too fast consumer movement induced by dragging loads, the meter-out orifice may be used to throttle the outlet flow appropriately. Therefore the valve is equipped with two integrated pressure transducers. A closed-loop control shuts the meter-out orifice as narrow that negative pressure and thus cavitation on the inlet side are prevented.

\section{Reference Application}

Loading cranes represent one of the most delicate applications in mobile hydraulics, as they call for fast and precise response on operator inputs. On this account, as reference basis for the flow-on-demand control, a forestry crane with conventional hydraulic-mechanical Load-Sensing system with pre compensators is selected. Being state-of-the-art, these hydraulic systems however suffer from the known disadvantages (cf. chap. 2.1). Especially crane movement anticipation and positioning precision are difficult when a state of pump saturation ends abruptly because a consumer

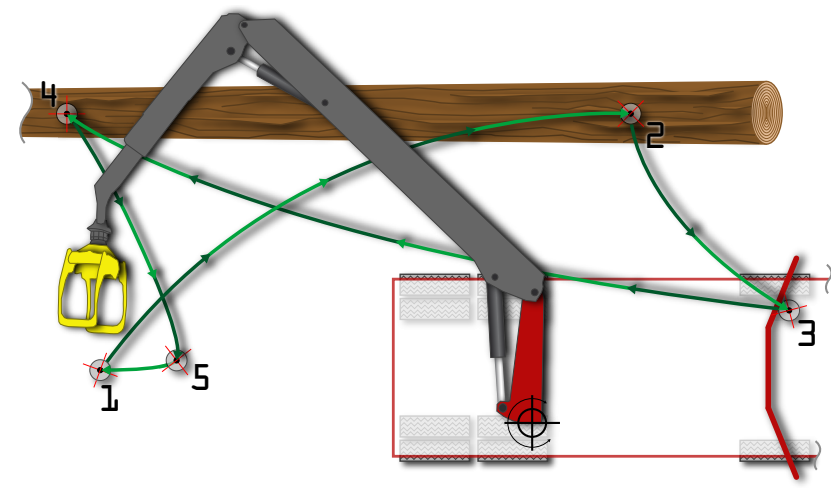

Figure 8: characteristic forestry crane duty cycle

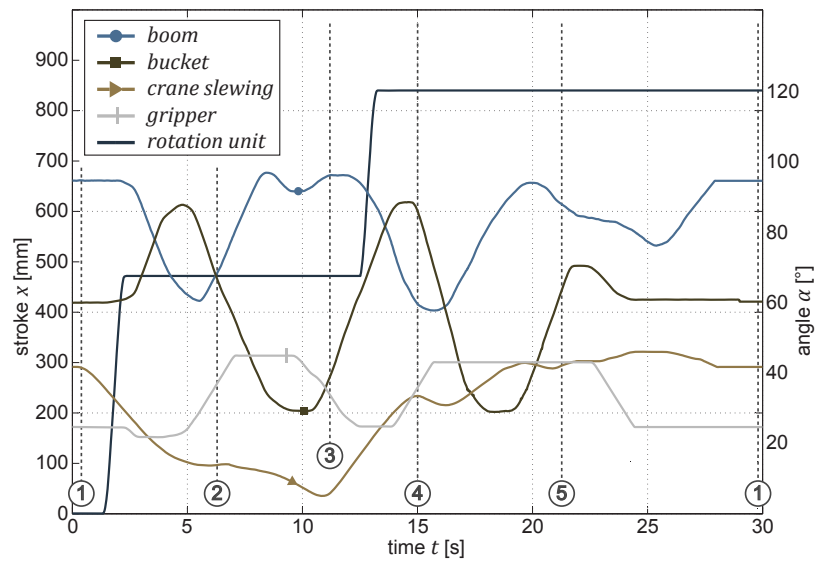

Figure 10: duty cycle-consumer movements with high flow rate is stopped and another consumer simultaneously being fine positioned, gets a flow peak as reaction.

The selected reference application, the feeder crane of a mobile log debarker (see Figure 9) is equipped with measurement technology to record hydraulic pressures and flow rates as well as cylinder strokes and velocities. The measurement results are used to parametrize and validate the LS simulation model (cf. chap. 4), consisting of five main consumers, namely crane slewing, boom- and bucket cylinders, gripper and associated rotation unit. The consumers are divided into two decoupled hydraulic circuits with variable displacement pumps being powered by a diesel engine. Additionally the machine has several auxiliary consumers, e.g. the telescopic arm and the hydraulic outriggers, not taken into account for the derived characteristic duty cycle (see Figure 8). The crane starts in position 1, grips the log a first time in position 2 and places it in position 3. Being gripped a second time in position 4 , the log is fed to the debarker from position 5 on. The log is released, leaving the crane in its initial position 1 , ready for the next cycle. The specific consumer movements, namely cylinder strokes and rotation angle, are displayed in Figure 10. The corresponding consumer loads are illustrated in Figure 11. For better appreciation, the numbers $(1-2-3-4-5-1)$ in those two figures indicate the slewing position of the crane, analogue to Figure 8.

Selected by availability and moreover its high workload and daily hours of service, the sample application represents

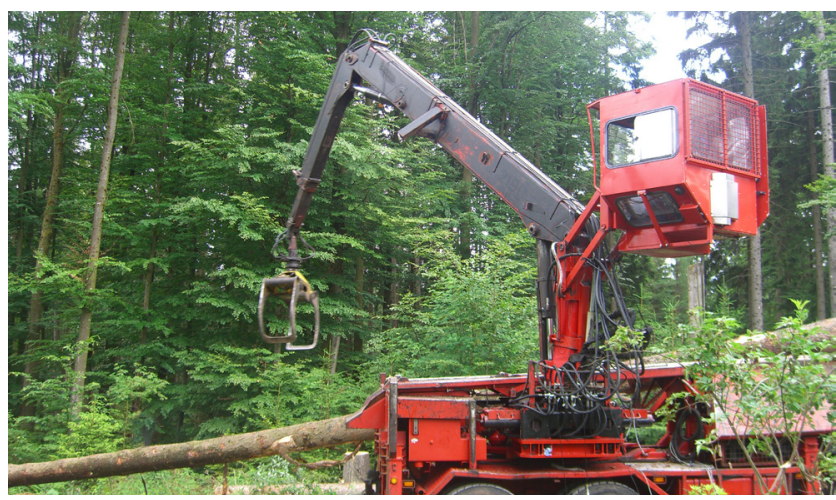

Figure 9: reference application - feeder crane of a mobile log debarker

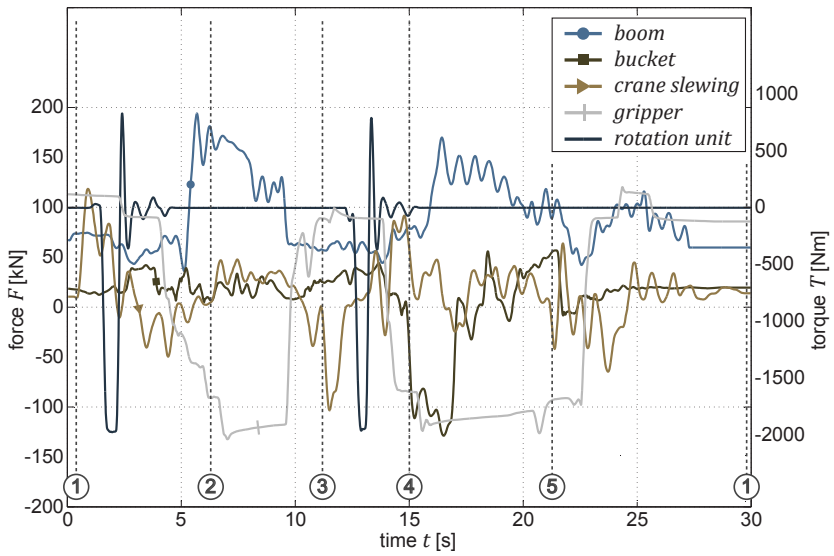

Figure 11: duty cycle-consumer loads 
other forestry crane applications with similar duty cycles like timber transporters, forwarders and wood chippers, implicating potential energy savings in the same range, at least concerning their cranes. The duty cycle of a timber transporter crane is exactly the same, also having two pickup points and two release points, only that the overall workload is wane due to major driving shares in the complete duty cycle of the transporter. Apart from usually only gripping a log once, duty cycles of forwarder and wood chipper cranes also correspond, despite the latter frequently using its telescopic arm to feed the chipper.

\section{Dynamic Simulation}

Simulation software is applied to develop suitable flow-ondemand concepts for the selected forestry crane application. The energy saving potentials are determined via dynamic simulation to evaluate whether the concepts are able to maintain the required performance. A dual circuit system with two hydraulic pumps and five actuators represents the main functions of the forestry crane (cf. chap 3). In the first instance the real Load-Sensing reference application is remodeled in the simulation environment. Followed by the
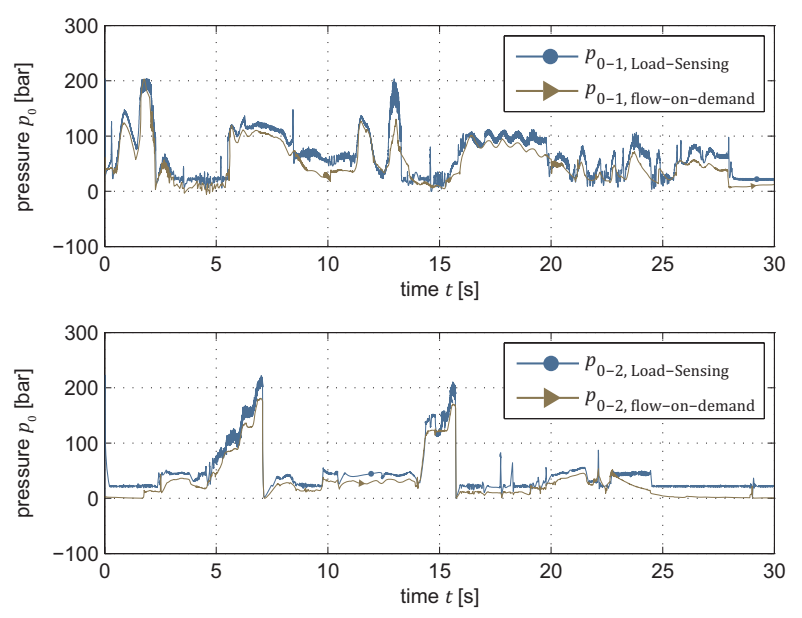

Figure 12: pressure history over duty cycle

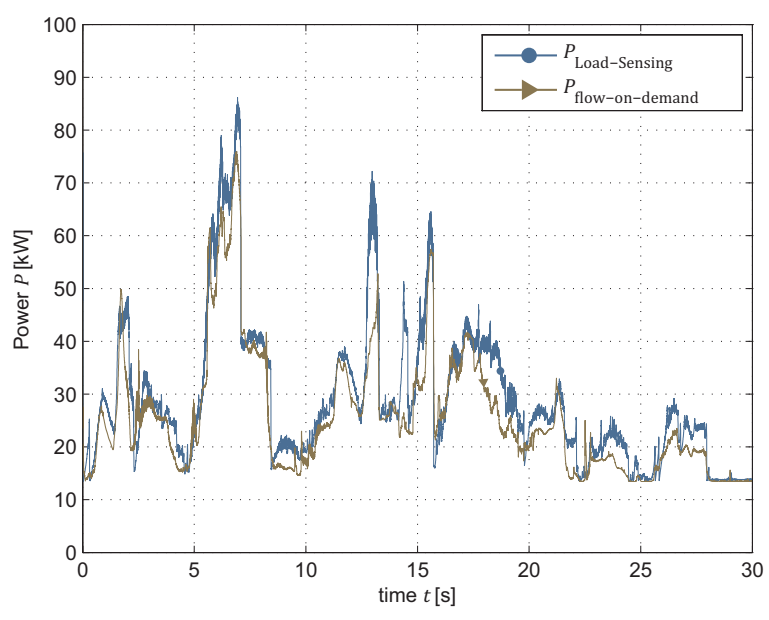

Figure 14: power consumption over duty cycle build-up of the simulation model of the flow-on-demand concept crane. To assure comparable simulation outcomes, the directional control valves of both systems are equally parametrized with the data of a series proportional valve with downstream pressure compensators and CAN communication, intended to be used in the latter prototype.

Comparing the flow-on-demand system to the LS reference, the simulation results reveal promising efficiency improvements. Figure 12 depicts the pressure histories of the two hydraulic pumps, clearly showing the pressure level of the flow-on-demand system lying always at least 10 bars beneath the LS-pump pressure. Analogous, the flow rate histories over the characteristic duty cycle are displayed in Figure 13. The flow rate margin between the two systems has a smaller magnitude than the pressure differences, but is anyhow existent. The reason is, LS systems require a small but constant signal oil flow that is bleed off to the reservoir. The fact, that LS systems keep up the pressure difference $\Delta p_{\text {LS }}$ even in idle duty cycle states, further decreases their energy efficiency. Contrary, in Flow-on-demand systems, the pressure drops to the minimum pump pressure in those situations. Additionally, the swiveling angle of the pump retreats to its minimum position. Figure 14 and Figure 15
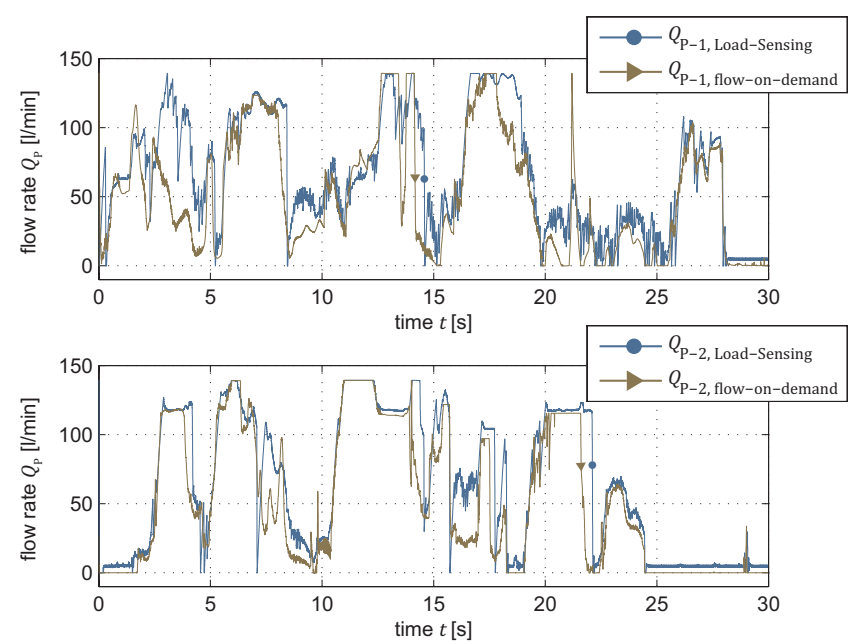

Figure 13: flow rate history over duty cycle

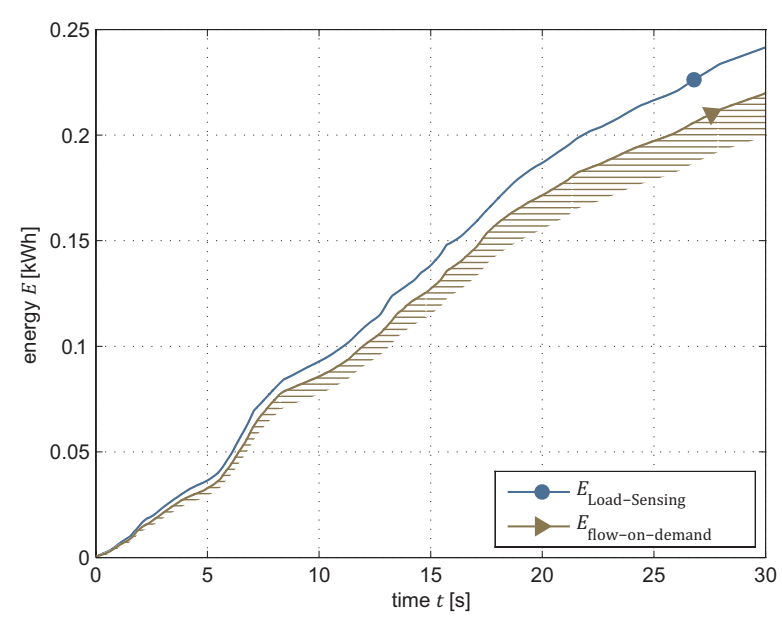

Figure 15: energy demand over duty cycle 
indicate the power consumption and energy demand of the entire system, calculated by eq. (6) and eq. (7):

$$
\begin{gathered}
P_{\text {mech }}=\frac{1}{\eta_{h m} \cdot \eta_{v o l}} \cdot P_{h y d}=\frac{1}{\eta_{h m} \cdot \eta_{v o l}} \cdot p_{0} \cdot Q_{P} \\
E_{\text {mech }}=\int P_{\text {mech }} d t
\end{gathered}
$$

The hatching in Figure 15 represents further decreased energy demand by applying the advanced control concepts, introduced in chapter 2.3. Related simulation outputs show energy saving potentials of 8 to 15 percent, depending on the regarded concept.

\section{Hydraulic Test Bench}

The operator in the simulation models is represented by a PI-controller. Apart from monitoring, that actuators are able to follow their theoretical path target, no qualitative feedback on system performance is given. Furthermore, not every single effect may be reproduced by simulation. Those arguments call for a hydraulic test bench. Especially the artificial undersupply may bear a trade-off between energy efficiency and system performance which has to be evaluated on a real system rather than in a simulation environment.
The layout of the hydraulic test stand (see Figure 16), being installed at the testing facilities of the Chair of Mobile Machines, includes an electrohydraulic displacement pump and three hydraulic consumers. Namely two differential cylinders (2) and (3) and a pressure adjustment orifice in bridge connection (1). The latter is used to represent loads of hydraulic motors. The bridge of four check valves enables flow reversion. The pressure adjustment orifices in the return flow lines of consumer (2) likewise represent hydraulic loads corresponding to external forces. Consumer (3) drives a mass mounted on a sled. To enable imprinting of dragging loads, consumer (2) and (3) may be coupled. The valve discs have pressure transducers integrated into their actuation units. Hence the presented electronic pressure limitation functions (cf. chap. 2.3) are easily implemented. A unique feature is included with the directional valve of consumer (3) as it has a segmented valve spool. Besides realization of a floating position, eventually occurring aftereffects concerning dragging loads may be addressed by controlling the meter-out orifice independently.

This setup allows for careful fine tuning and profound testing of the developed flow-on-demand control. Moreover the dynamic performance of the advanced control concepts, evolved from simulation, may be validated on the real system.

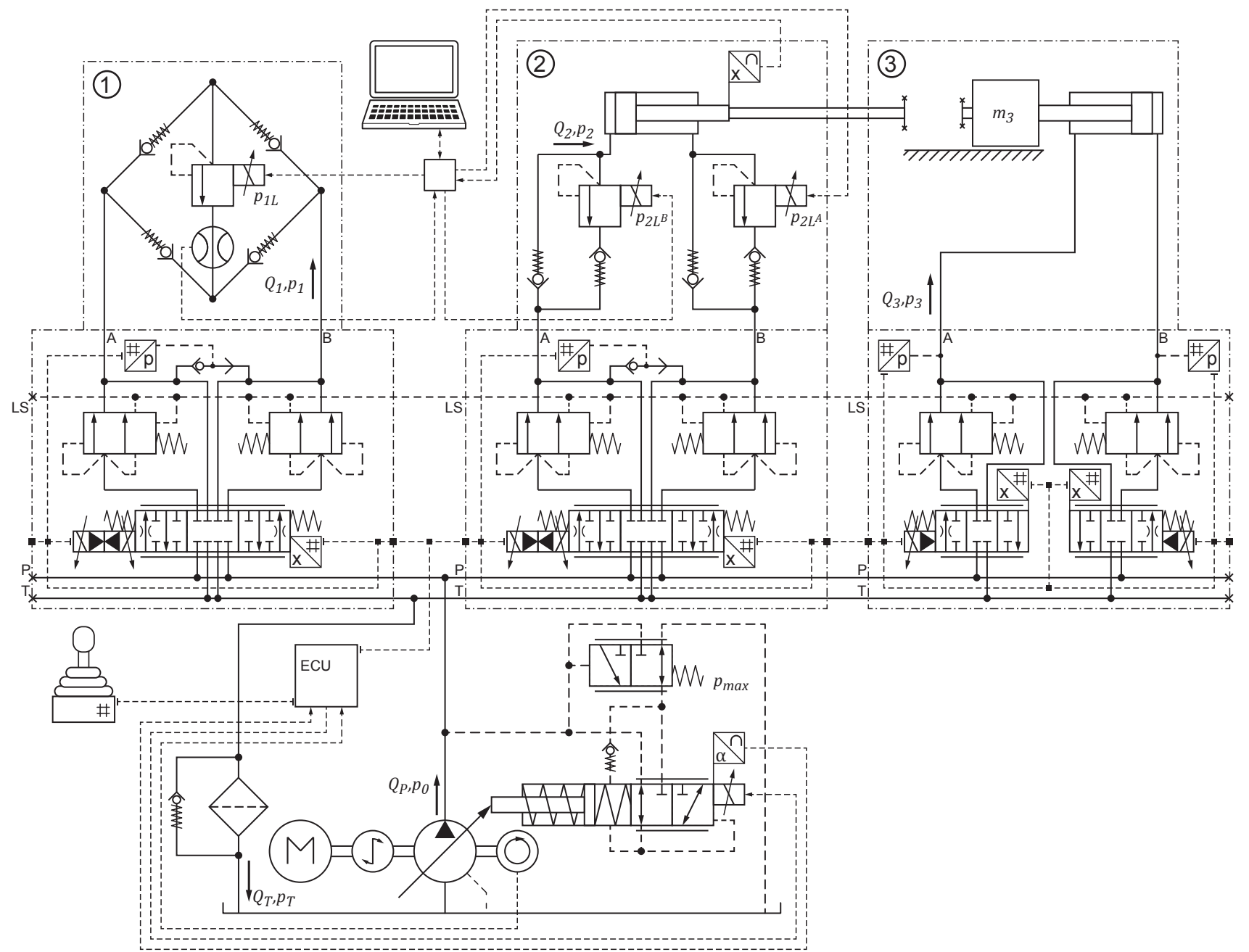

Figure 16: Flow-on-demand control hydraulic test bench layout 


\section{Outlook}

Flow-on-demand hydraulic systems offer the prospect of a sustainable reduction of energy demand and fuel consumption. In the course of the presented project a prototype will be build up to verify the potential. At large further enhancements and functional combinations are thinkable and call for future research.

\subsection{Forestry Crane Prototype}

The reference machine is equipped with the related electrohydraulic components and control unit to complete intensive field tests of the flow-on-demand concept. Comparison to the Load-Sensing measurements will reveal its true energy savings. The machine operators shall evaluate the improved operability in terms of oscillation avoidance, cold start performance and maneuverability. The prototype serves as demonstration object for forestry machine manufacturers and will lead the path for the introduction of electrohydraulics into an anyway innovation friendly branch of industry.

\subsection{Recuperation}

The breakup of the flow dependence between consumers and displacement pump allows for a facile integration of recovery units for potential energy. Furthermore the pump may be used to charge hydraulic accumulators in otherwise idle states or partial load situations.

\section{Acknowledgments}

The presented research is funded by the Deutsche Bundesstiftung Umwelt (DBU) with the goal to improve the energy efficiency of forestry machinery. The authors are pleased to thank for the endorsement of the project and the cooperation. The hydraulic simulation software DSHplus is provided by the company Fluidon $\mathrm{GmbH}$ free of charge. A communication interface for the Software-in-the-Loop development of the ECU is provided by the company Vector Informatik $\mathrm{GmbH}$. The components for the hydraulic load equipment of the test bench are donated by HAWE Hydraulik SE. Special thanks are directed to Bucher Hydraulics $\mathrm{GmbH}$ for the support on the valve block, which is the key feature of the presented flow-on-demand hydraulic system.

\section{Nomenclature}

\begin{tabular}{lll}
\hline Designation & Denotation & Unit \\
\hline$A_{0}$ & restriction area & {$\left[\mathrm{mm}^{2}\right]$} \\
$A, B$ & consumer port & - \\
$\alpha_{\mathrm{D}}$ & flow coefficient & - \\
$C$ & consumer & - \\
$\mathrm{CAN}$ & Controller Area Network & - \\
$\mathrm{CC}$ & closed center & - \\
$E$ & energy & {$[\mathrm{Wh}]$}
\end{tabular}

\begin{tabular}{|c|c|c|}
\hline Designation & Denotation & Unit \\
\hline ECU & electronic control unit & - \\
\hline $\mathrm{fp}$ & functional principle & - \\
\hline hm & hydraulic-mechanical & - \\
\hline$L$ & load & - \\
\hline LS & Load-Sensing (port) & - \\
\hline$\eta_{\text {th }}$ & degree of efficiency & - \\
\hline$O C$ & open center & - \\
\hline$P$ & power & {$[\mathrm{kW}]$} \\
\hline$P$ & pump (port) & - \\
\hline$p$ & pressure & {$[\mathrm{bar}]$} \\
\hline$P C$ & pressure compensator & - \\
\hline$Q$ & flow rate & {$[1 / \mathrm{min}]$} \\
\hline$\rho$ & density & {$\left[\mathrm{kg} / \mathrm{m}^{3}\right]$} \\
\hline $\mathrm{sp}$ & saving potential & - \\
\hline$T$ & tank port & - \\
\hline th & theoretical & - \\
\hline thr & throttling & - \\
\hline vol & volumetric & - \\
\hline
\end{tabular}

\section{References}

[1] M Djurovic. Energiesparende Antriebssysteme für mobile Arbeitsmaschinen ,Elektrohydraulisches Flow Matching “. PhD thesis, Techn. Univ., Dresden, 2007

[2] T Fedde. Elektrohydraulische Bedarfsstromsysteme am Beispiel eines Traktors. PhD thesis, Techn. Univ., Braunschweig, 2007

[3] R Finzel. and S Helduser. Energy-Efficient Electro-Hydraulic Control Systems for Mobile Machinery / Flow Matching. Proc. of $6^{\text {th }}$ International Fluid Power Conference, Dresden, 2008

[4] M Axin, B Eriksson and J-O Palmberg. Energy Efficient Load Adapting System without Load Sensing - Design and Evaluation. Proc. of the $11^{\text {th }}$ Scandinavian International Conference on Fluid Power, Linköping, 2009

[5] R Finzel. Elektrohydraulische Steuerungssysteme für mobile Arbeitsmaschinen. $\mathrm{PhD}$ thesis, Techn. Univ., Dresden, 2010

[6] B Eriksson and J-O Palmberg. How to Handle Auxiliary Functions in Energy Efficient, Single Pump, Flow Sharing Mobile Systems. Proc. of $7^{\text {th }}$ International Fluid Power Conference, Aachen, 2010

[7] M Axin, B Eriksson, J-O Palmberg and P Krus. Dynamic Analysis of Single Pump, Flow Controlled Mobile Systems. Proc. of the $12^{\text {th }}$ Scandinavian International Conference on Fluid Power, Tampere, 2011 
[8] M Axin, J-O Palmberg and P Krus. Optimized Damping in Cylinder Drives Using the Meter-out Orifice - Design and Experimental Verification. Proc. of $8^{\text {th }}$ International Fluid Power Conference, Dresden, 2012

[9] US3866419. Integrated Pressure Compensated Load Sensing System. Parker-Hannifin Corp. United States Patent, 1975

[10] K Steindorff. Untersuchungen zur Energierückgewinnung am Beispiel eines ventilgesteuerten hydraulischen Antriebs. PhD thesis, Techn. Univ., Braunschweig, 2010

[11] R Rahmfeld. Development and Control of Energy Saving Hydraulic Servo Drives for Mobile Systems. Fortschr.-Ber. VDI Reihe 12 Nr. 527. Düsseldorf: VDI Verlag, 2002

[12] R Rahmfeld, M Ivantysynova and J Weber. Displacement Controlled Wheel Loader - a simple and clever Solution. Proc. of $4^{\text {th }}$ International Fluid Power Conference, Dresden, 2004

[13] K Heybroek, J-O Palmberg, J Lillemets, M Lugnberg and M Ousbäck. Evaluating a Pump Controlled Open Circuit Solution. Proc. of $51^{\text {st }}$ National Conference on Fluid Power, Las Vegas, NV, 2008

[14] D Peitsmeyer. Elektrifizierung der Arbeitsausrüstung mit Zylinderantrieben. Proc. of 7. Kolloquium Mobilhydraulik, Karlsruhe, 2012

[15] B Zähe. Energiesparende Schaltungen hydraulischer Antriebe mit veränderlichem Versorgungsdruck und ihre Regelung. $\mathrm{PhD}$ thesis, RWTH Aachen, 1993

[16] DE 10342037 A1. Steueranordnung und Verfahren zur Druckmittelversorgung von zumindest 2 hydraulischen Verbrauchern. German Patent, 2003

[17] M Djurovic, S Helduser and G Keuper. Neue Lösungen zum elektrohydraulischen Load-Sensing. Proc. of $4^{\text {th }}$ International Fluid Power Conference, Dresden, 2004 